\title{
ESTUDO DA INFLUENCIA DA TEMPERATURA NA OBTENÇÃO DE HIDROXIAPATITA PARA FINS BIOMÉDICOS
}

\author{
T. C. S. PEREIRA ${ }^{1}$, G. A. FERNANDES ${ }^{1}$ \\ ${ }^{1}$ Universidade Federal de Itajubá, Instituto de Engenharia Mecânica \\ E-mail para contato: thaticsp_ita@hotmail.com
}

\begin{abstract}
RESUMO - A hidroxiapatita (HA) é uma cerâmica amplamente utilizada como biomaterial, pois promove a ósteo-integração, apresentando composição química similar ao tecido ósseo. A sua síntese via precipitação química é vantajosa, devido ao seu baixo custo e simplicidade. Neste trabalho foi realizada a síntese de HA pelo método de precipitação química via úmida, utilizando uma reação de neutralização entre o ácido fosfórico e o hidróxido de cálcio, a uma temperatura de $60^{\circ} \mathrm{C}$. O biomaterial obtido foi separado em três frações: uma para comparação e duas para calcinação em temperaturas diferentes $\left(800\right.$ e $\left.1000^{\circ} \mathrm{C}\right)$. O pó produzido foi caracterizado por espectroscopia de infravermelho com transformada de Fourier (FTIR) e difração de raios X (DRX). Os resultados mostraram que foi produzida uma hidroxiapatita com alto grau de pureza.
\end{abstract}

\section{INTRODUÇÃO}

A hidroxiapatita, $\mathrm{Ca}_{10}\left(\mathrm{PO}_{4}\right)_{6}(\mathrm{OH})_{2}$, dentre os fosfatos de cálcio, é a biocerâmica mais estudada e a mais utilizada para finalidades clínicas, principalmente por se tratar do componente majoritário da fase mineral de ossos e dentes (30 a 70\%). Portanto, as células não diferenciam a hidroxiapatita da superfície óssea (bioatividade), indicando grande similaridade química superficial entres ambos (Mears, 1979).

Diversas técnicas vêm sendo desenvolvidas para a síntese do pó de HA devido a suas crescentes aplicações (Boschi, 1993). Dentre os vários métodos existentes, o mais utilizado é o de precipitação via úmida. Esta técnica apresenta baixo custo e simplicidade, quando comparada aos métodos tradicionais; além de produzir hidroxiapatita com características similares às do tecido ósseo e dentário.

Apesar de suas vantagens, a precipitação via úmida pode gerar produtos não estequiométricos e mistura de fases, o que se deve à presença de vacâncias e substituições iônicas na rede, tais como carbonatos, hidrogeno-fosfatos, potássio, sódio, nitrato e cloreto (Koutsopoulos, 2002).

Os processos de precipitação consistem na adição de grupos fosfatos a suspensões que contenham íons cálcio, podendo partir de diferentes reagentes. A reação de neutralização que utiliza ácido ortofosfórico e hidróxido de cálcio apresenta maior potencial para produção da hidroxiapatita uma vez que se tem apenas água como subproduto da reação. 
O tempo de envelhecimento e a cinética de reação são variáveis críticas para a pureza e características cristalográficas do material obtido (Rigo et. al., 2007). Segundo Lourenço et al. (2009), reações de obtenção em temperaturas mais altas (a partir de $80^{\circ} \mathrm{C}$ ), permitem a obtenção de pós mais cristalinos. Diferentes temperaturas de calcinação do pó obtido podem alterar a fase presente no sólido, pois cada uma das fases dos fosfatos de cálcio apresenta diferentes estabilidades térmicas e propriedades físicas.

Diante deste grande número de variáveis presentes, este trabalho teve como objetivo avaliar o grau de pureza da HA sintetizada a um valor de temperatura mais baixo do que o recomendado pela literatura e estudar a influência das temperaturas de calcinação em suas propriedades estruturais.

\section{METODOLOGIA}

A hidroxiapatita foi preparada pelo método de precipitação via úmida, no qual foram utilizados hidróxido de cálcio e ácido fosfórico como reagentes. A solução de ácido fosfórico $0,3 \mathrm{M}$ foi adicionada com controle de vazão $(0,1 \mathrm{~mL} / \mathrm{s})$ à solução de hidróxido de cálcio $0,5 \mathrm{M}$ previamente aquecida à temperatura de $60^{\circ} \mathrm{C}$, sob agitação constante.

$\mathrm{O}$ pH foi controlado por meio da adição de $\mathrm{NH}_{4} \mathrm{OH}$, permanecendo entre 9,0 e 9,5. O precipitado foi envelhecido por um período de $24 \mathrm{~h}$ na solução mãe, na qual decantou. Após esse período a suspensão foi filtrada a vácuo e o precipitado foi seco em estufa a $80^{\circ} \mathrm{C}$ por $24 h$.

O pó de hidroxiapatita obtido foi desaglomerado em um almofariz de ágata e dividido em três frações, uma foi reservada para comparação, e as demais passaram pelo processo de calcinação, a $800^{\circ} \mathrm{C}$ e $1000^{\circ} \mathrm{C}$, durante duas horas.

Os pós foram submetidos à análise por espectroscopia de infravermelho por transformada de Fourier (FTIR) e difração de raios X (DRX). As fases cristalinas foram identificadas por difração de raios-X. A análise foi conduzida a temperatura ambiente em um equipamento Shimadzu XRD-6000 a $40 \mathrm{kV}$ e $30 \mathrm{~mA}$ e com um comprimento de onda $\lambda \mathrm{CuK} \alpha$ $=0.154 \mathrm{~nm}$. As amostras em forma de pó foram analisadas em um intervalo de varredura de $2 \theta$ entre 20 e 80 graus a uma taxa de $1,2 \% \mathrm{~min}$.

\section{RESULTADOS E DISCUSSÕES}

\subsection{Resultados dos ensaios de FTIR}

A partir dos espectros de absorção no infravermelho obtidos para as amostras de hidroxiapatita não calcinada (Figura 1), calcinada a $800^{\circ} \mathrm{C}$ (Figura 2) e calcinada a $1000^{\circ} \mathrm{C}$ (Figura 3), é possível verificar similaridade entre os resultados obtidos.

As bandas presentes representam a fase de HA, confirmando a eficácia da síntese. Picos em torno de 963, 1024 e $1087 \mathrm{~cm}^{-1}$, representam o grupamento $\mathrm{PO}_{4}{ }^{-3}$, que ficam mais evidentes com a sinterização; a banda em $3576 \mathrm{~cm}^{-1}$ representa o grupamento $\mathrm{OH}^{-}$. Os espectros também mostram vestígios de $\mathrm{CO}_{3}{ }^{-2}$ em torno de 870 e na faixa de 1400 a 1500 , que vão desaparecendo com o aumento da temperatura de calcinação. 
Figura 1 - Espectro da amostra de hidroxiapatita não calcinada.

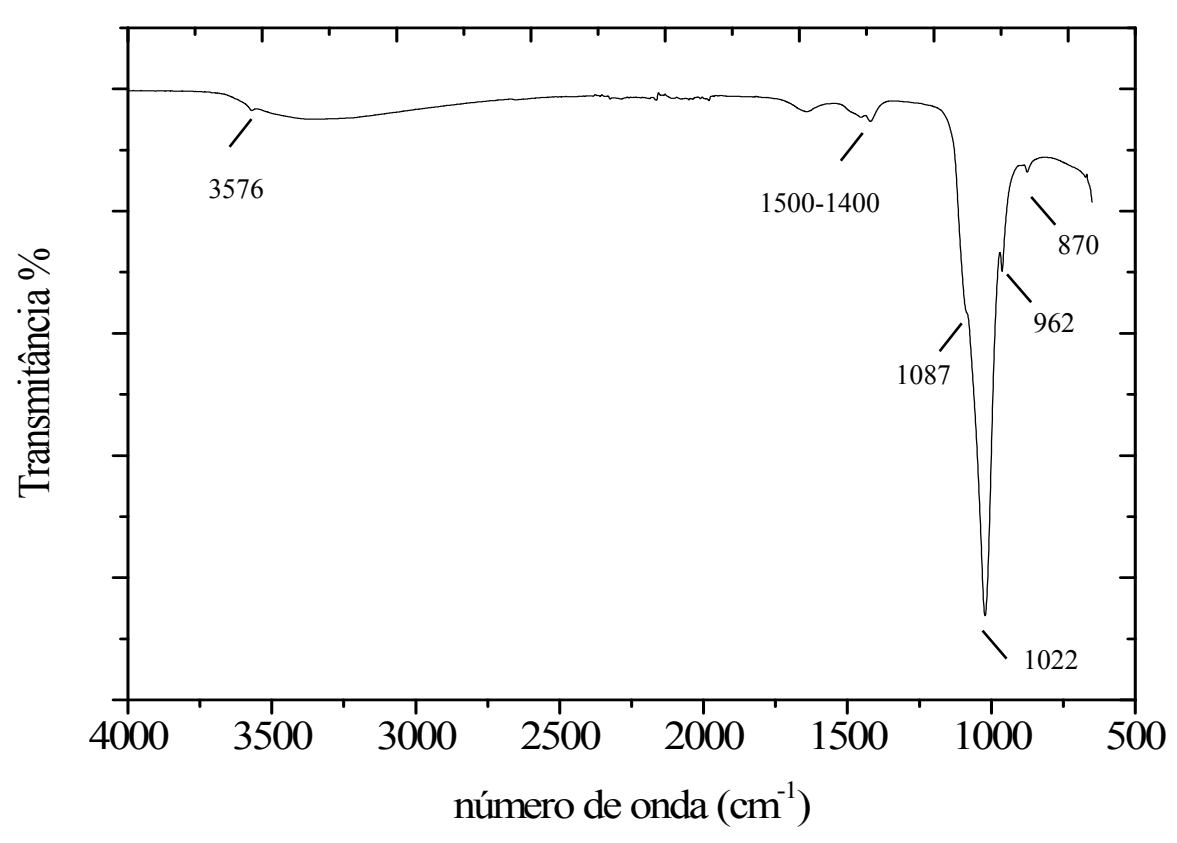

Figura 2 - Espectro da amostra de hidroxiapatita calcinada a $800^{\circ} \mathrm{C}$.

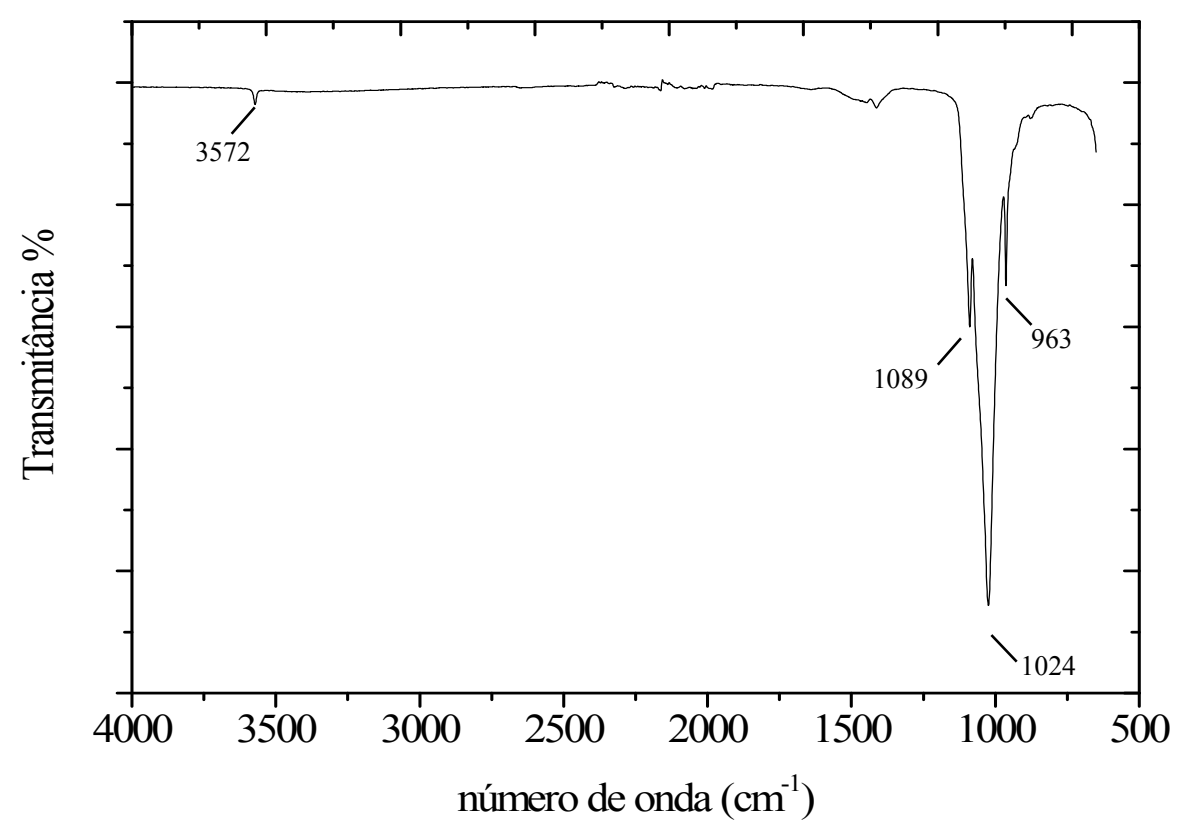


Figura 3 - Espectro da amostra de hidroxiapatita calcinada a $1000^{\circ} \mathrm{C}$.

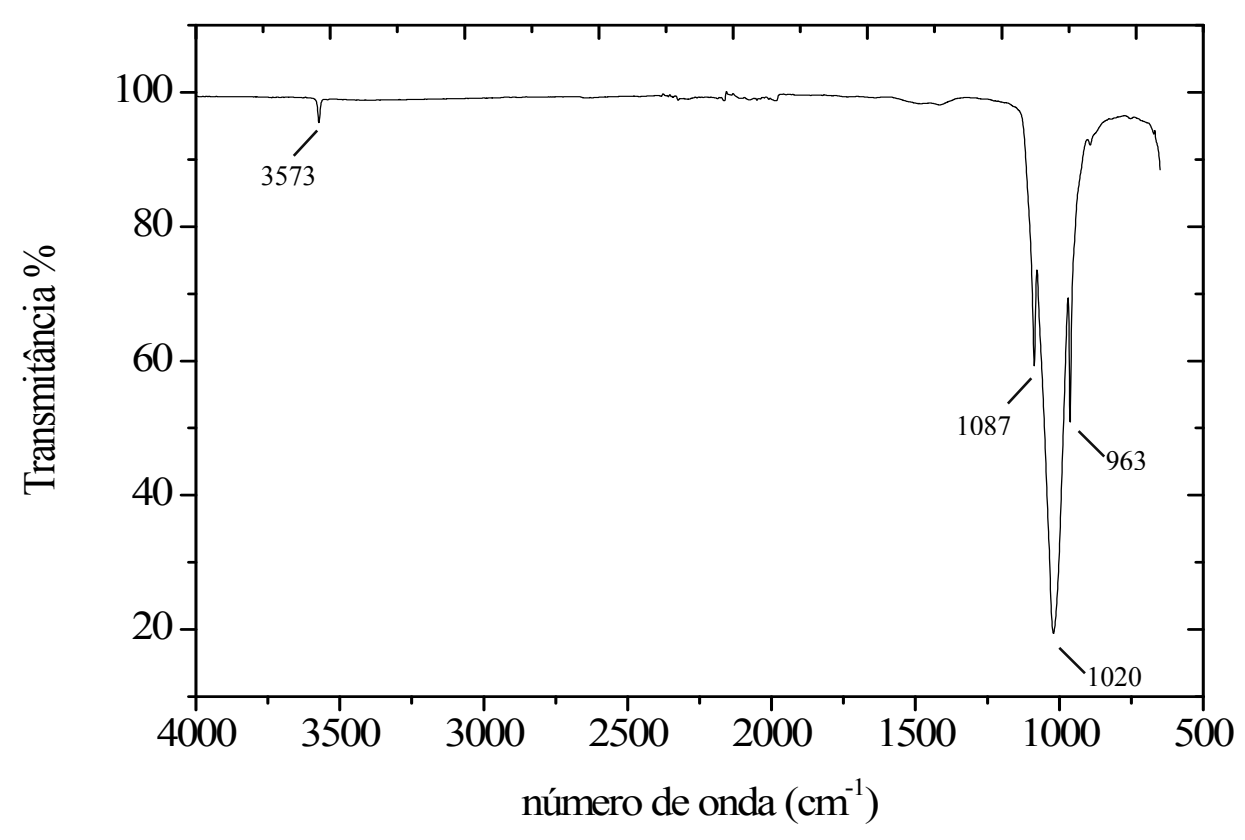

\subsection{Resultados dos ensaios de DRX}

Os difratogramas de raios- $\mathrm{X}$ das amostras de hidroxiapatita sem calcinar e calcinadas a temperaturas de $800^{\circ} \mathrm{C}$ e $1000^{\circ} \mathrm{C}$, são mostrados nas figuras 4,5 e 6 respectivamente.

Figura 4 - Difratograma da amostra de hidroxiapatita não calcinada.

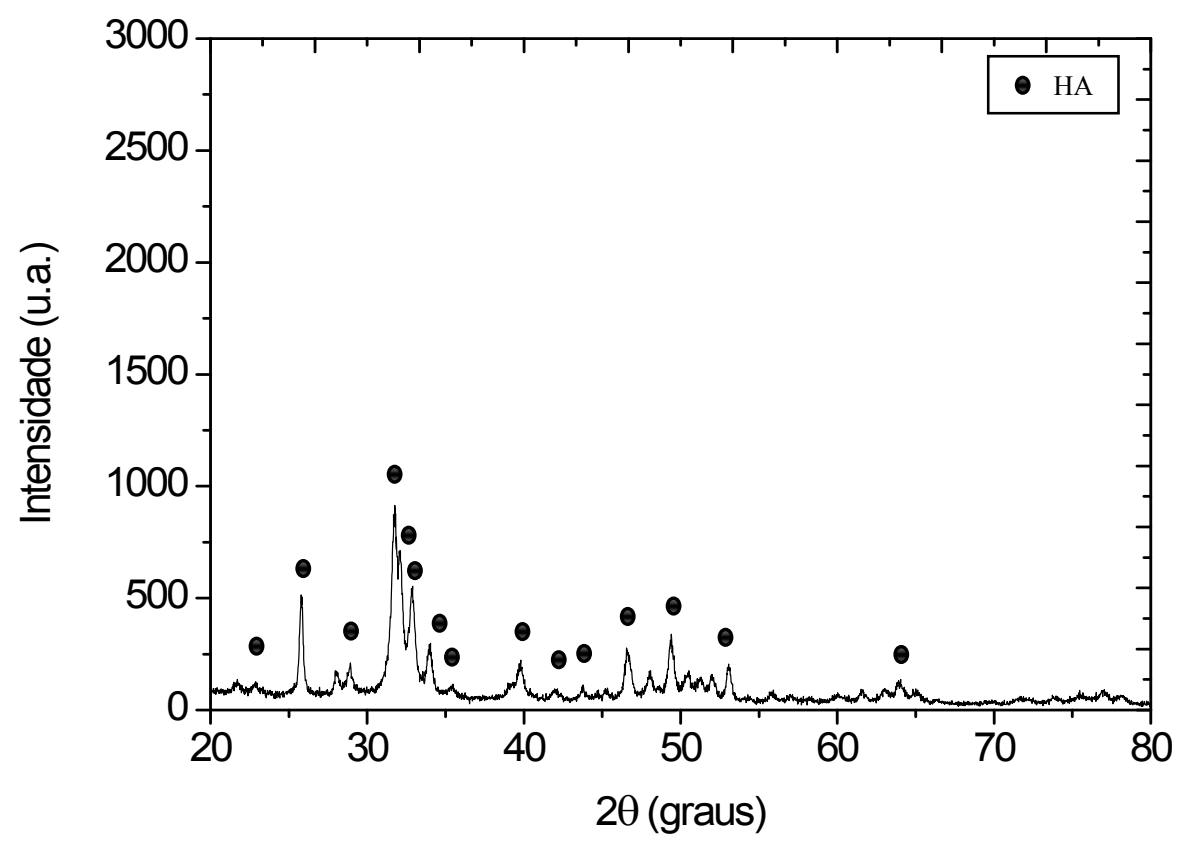


Figura 5 - Difratograma da amostra de hidroxiapatita calcinada a $800^{\circ} \mathrm{C}$

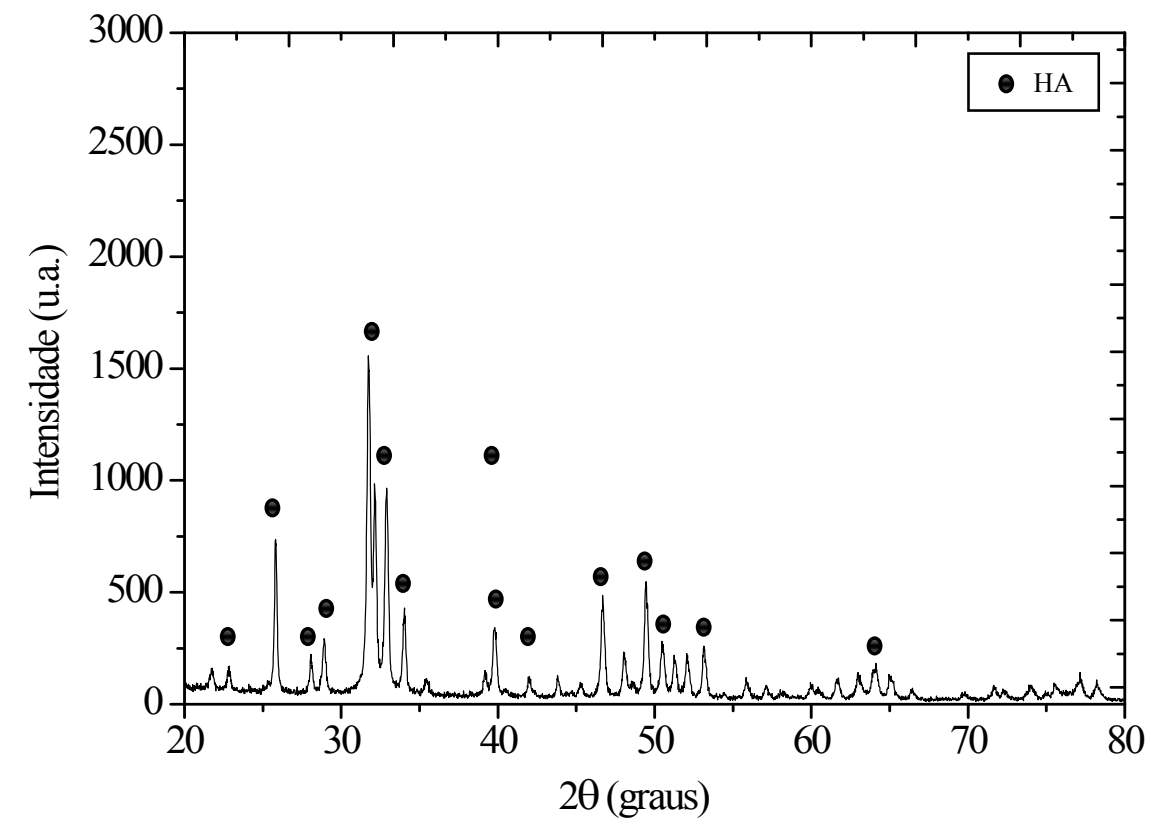

Figura 6 - Difratograma da amostra de hidroxiapatita calcinada a $1000^{\circ} \mathrm{C}$

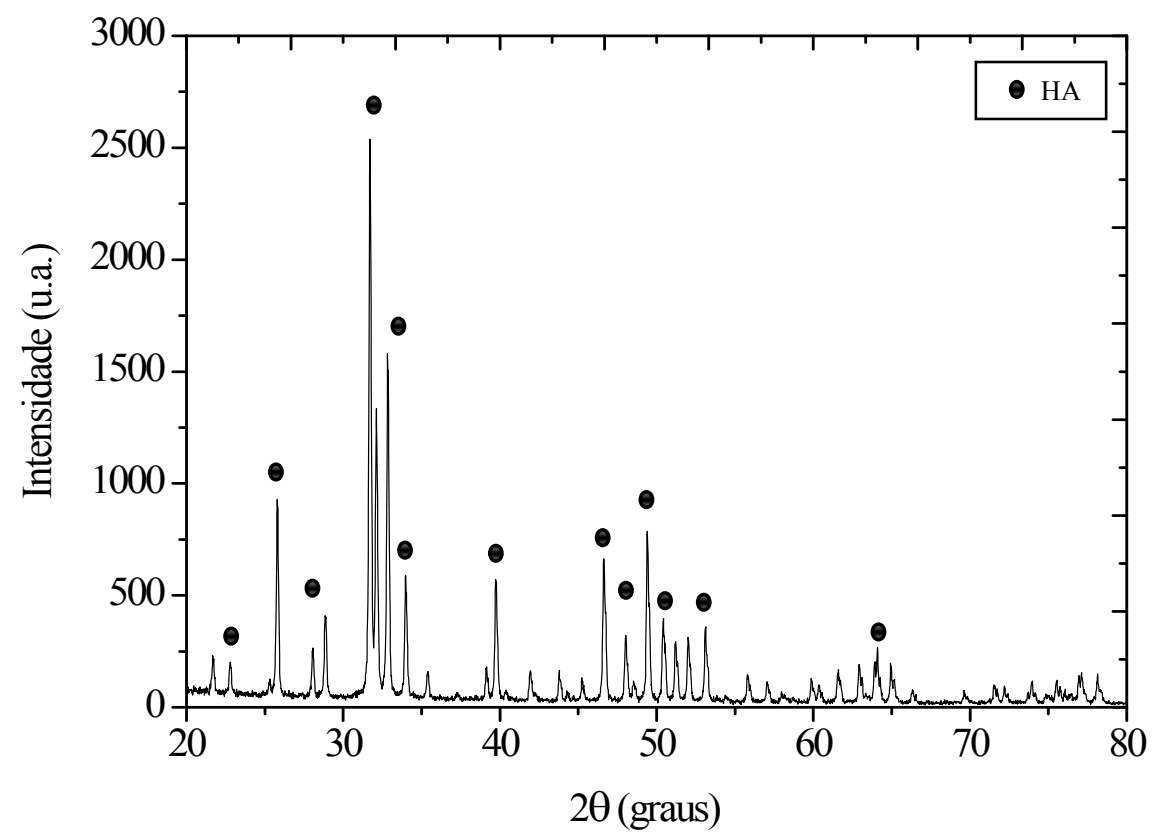


Pelos difratogramas obtidos (Figura 4 a Figura 6) é possível constatar que as amostras apresentam as fases características de uma hidroxiapatita (indicadas pelos pontos negros acima dos picos de cada difratograma), ou seja, as bandas nos difratogramas representam as fases das quais a hidroxiapatita é formada, não mostrando a formação de nenhuma fase diferente destas.

Os difratogramas também mostram que com o aumento na temperatura de calcinação os picos ficam mais bem definidos e com maior intensidade, o que indica o aumento na cristalinidade do pó, ou seja, as amostras calcinadas apresentam estruturas mais cristalinas que a amostra não calcinada. Isso ocorre porque a temperatura de calcinação influencia na fase presente do pó, devido às diferentes propriedades físicas e estabilidades térmicas das fases presentes nos fosfatos de cálcio.

\section{CONCLUSÃO}

A caracterização do material mostrou que o pó produzido pelo método da precipitação apresentou apenas fases cristalinas de hidroxiapatita. Então a temperatura de $60^{\circ} \mathrm{C}$ é suficiente para síntese de HA com alto grau de pureza, sendo que todos os reagentes foram consumidos durante a reação e não houve a formação de outros tipos de fosfatos de cálcio como subprodutos, ao menos não em quantidade suficiente para ser detectada pela análise de DRX. Concluiu-se também que a temperatura de calcinação influencia diretamente na fase obtida, sendo aconselhável a calcinação após a síntese da hidroxiapatita para se obter um produto com maior cristalinidade.

\section{REFERÊNCIAS}

BOSCHI, A. O. O que é necessário para que um material possa ser considerado um biomaterial? Anais do III Encontro Nacional de Biomateriais. São Paulo, p. 63-75, out., 1993.

KOUTSOPOULOS, S. Synthesis and characterization of hydroxyapatite crystals: a review study on the analytical methods. J. Biomed.l Mater. Res., v. 62, p. 600-612, 2002.

LOURENÇO, B. H. G.; SOUSA, E.; SILVA, G. Avaliação da influência das temperaturas de obtenção e calcinação na síntese de hidroxiapatita. Anais do IX Encontro Latino Americano de Pós-Graduação. São José dos Campos - SP, 2009.

MEARS, D.C. Materials and Orthopaedic Surgery. Baltimore.: Williams and Wilkms Co., 1979.

RIGO, E. C. S.; GEHRKE S. A.; CARBONARI, M. Síntese e caracterização de hidroxiapatita obtida pelo método da precipitação. Rev. Dental Press Periodontia Implantol., v. 1, n. 3 , p. 39-50, 2007. 